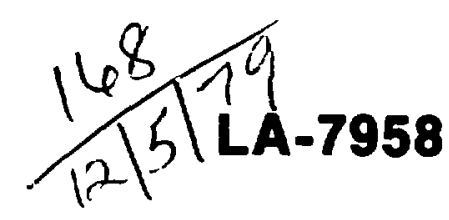

$$
\text { DR } 36.5
$$

Determination of Thorium in Plutonium-Thorium Oxides and Carbides

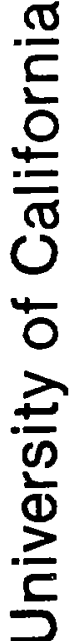




\title{
Determination of Thorium in Plutorium-Thorium Oxides and Carbides
}

\author{
L. F. Walker \\ D. J. Temer
}

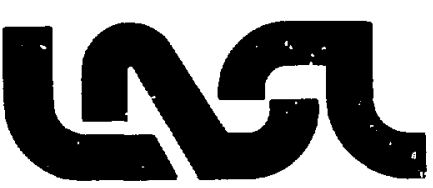




\title{
DETERMINATION OF THORIUM IN PLUTONIUM-T'HORIUM OXIDES AND CARBIDES
}

by

\author{
L. F. Walker and D. J. Temer
}

\begin{abstract}
Thorium is determined in $(\mathrm{Pu} T h) \mathrm{C}$ and $(\mathrm{PuTh}) \mathrm{O}_{2}$ by complexometric titration with et hylenediaminetetraacetic acid (EDTA) following separation on anion-exchange resin. Carbides are first oxidized by ignition in air at about $8000^{\circ} \mathrm{C}$. Oxide or oxidized carbide samples are dissolved in acids by the sealed-reflux technique or by heating in beakers. The plutonium is selectively sorbed from the $12 M$ hydrochloric acid solution of the fuel on a Bio-Rad AG1-X2 anion-exchange resin column, and the eluted thorium is titrated with EDTA using xylenol orange as the indicator. The average recovery of thorium in 20 samples is $99.98 \%$ with a relative standard deviation of $0.07 \%$.
\end{abstract}

\section{INTRODUCTION}

In order to awid the use of plutonium in reactor fuel. a Th- ${ }^{23}$ ( fuel cycle is being comsidered as a possible alternative. A stand-in fuel, in which plutonium has been substituted for the ${ }^{233}$ : has been ured. Because thorium cannot be determined directly in the presence of plutonium or uranium, a need exists for a method of determining thorium in carbides, oxides, or nitrides, of ( $\left.\mathrm{Pu}-\mathrm{T}^{\mathrm{h}} \mathrm{h}\right)$ or $\left(\mathrm{L}^{\mathrm{*}}-\mathrm{Th}\right.$ ) reactor fuel.

A method for determining thorium in solution is well known.' 'Thorium cannot be determined by complexometric titration with ethylenediaminetetraacetic acid (EDTA) in the presence of eit her plutonium or uranium because (1) plutonium and uranium form stable EIJTA complexes, ${ }^{2}$ and (2) the plutonium ion color masks the xylenol orange end-point. so a separation before analysis is necessary.

Thorium ${ }^{+4}$ is separated from $\mathrm{Pu}^{4+}$ using anionexchange resin ${ }^{3}$ in $12 M$ hydrochloric acid. The thorium ${ }^{+4}$ passes through the column while the $\mathrm{Pu}^{4-}$ is retained. The thorium is collected and fumed to druness with perchloric and nitric acids to eliminate carbonaceous materials that cause difficulties in end-point detection. The residue is taken up in water. the $\mathrm{pH}$ adjusted to 2.5 , xylenol orange is added, and the thorium is titrated with a dilute solution of $\mathrm{Na}_{4}$ lisTA. To maintain the $\mathrm{pH}$ at $2.5+0.1$ during the titration the tetrasodium salt of EDTA is prieferred to the disodium salt. The $\mathrm{Na}_{4}$ EDTA titrant is standardized against a thorium reference solution the same day the samples are analyzed.

\section{APPARATUS AND REAGENTS}

\section{Apparatus}

Balance. A single-pan Mettler balance with hook to hold weight burette, sensitivity of $\pm 0.1 \mathrm{mg}$.

Column. Ion-exchange resin column as shown in Fig. 1. 


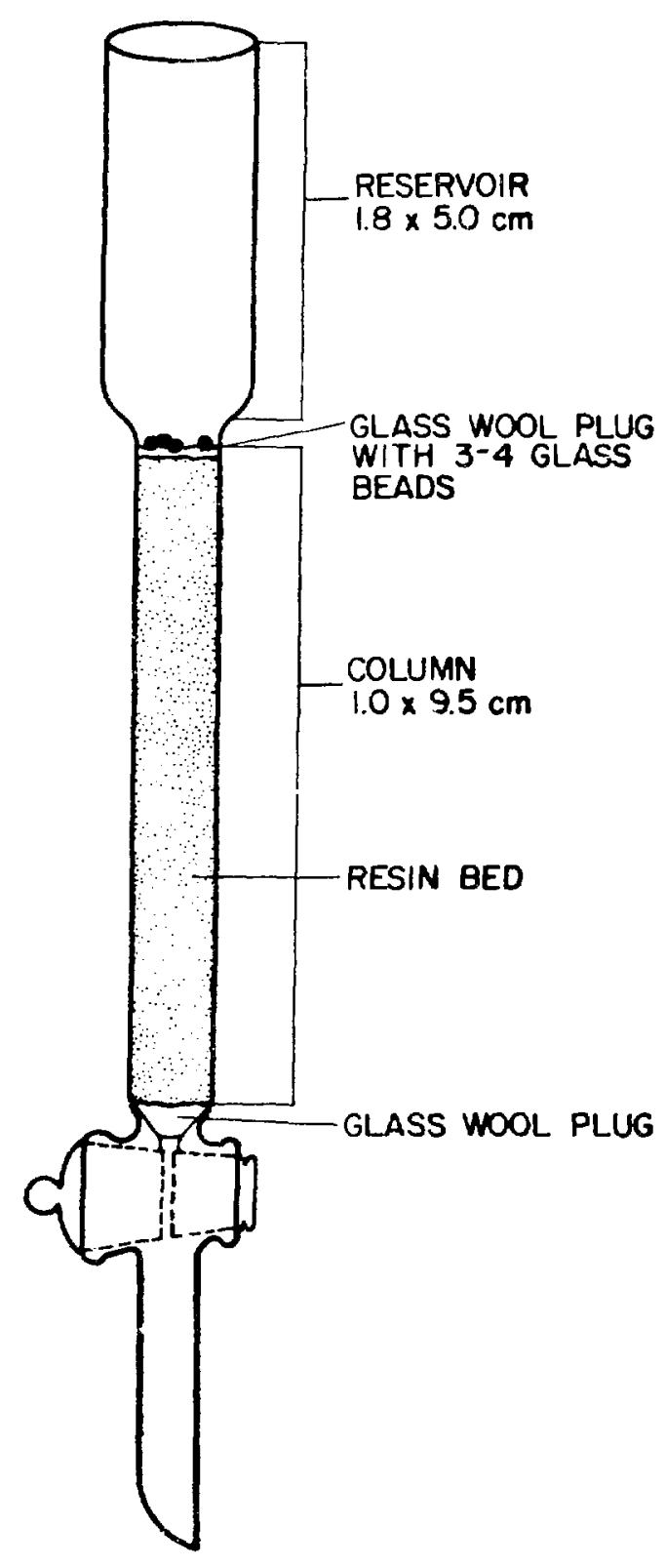

Fig. 1.

Ion-exchange resin column.

Electrode. A semi-micro, combination $\mathrm{pH}$ electrode.

Weight burette. A modified Friedman LaMer burette, as shown in Fig. 2.

Miscellaneous lab equipment. $\mathrm{pH}$ meter, hot

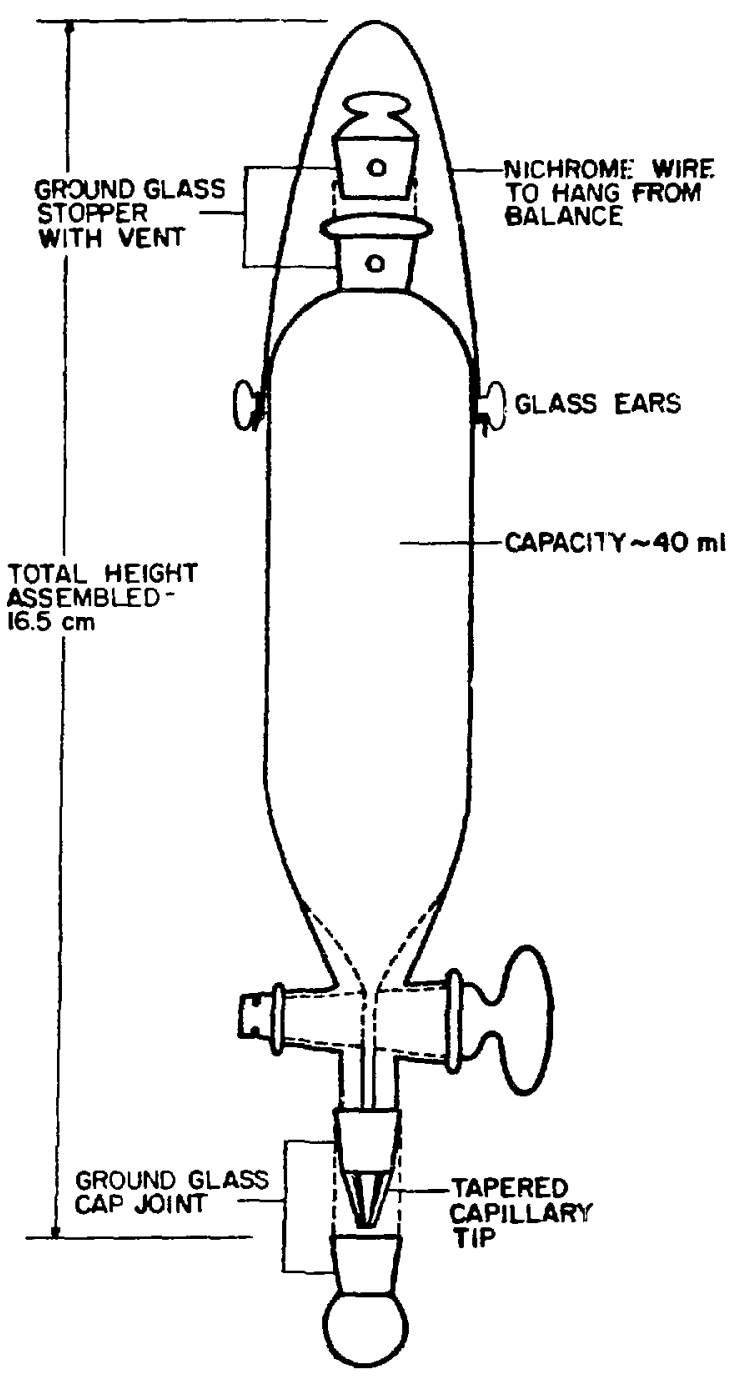

Fig. 2.

Weight burette.

plate, magnetir mixer, beakers (50 or $100 \mathrm{~m} \ell$ ) and other common glassware.

Polyethylene bottle. A size $9 \ell$ bottle with dispensing spigot to store $\mathrm{Na}_{4}$ EDTA solution $\left(\mathrm{Na}_{4}\right.$ EDTA solutions etch glass).

\section{Reagents}

EDTA. Baker analyzed tetrasodium salt, $0.025 \mathrm{M}$.

Hydrochloric Acid. 12M, $1 M, 0.1 M$, reagent grade. 
Ion-exchange resin. Bio-Rad AG1-X2, 100-200 mesh.

Nitric acid. $15.5 M$, reagent grade.

Sodium hydroxide. $0.3 M$, reagent gracie.

Perchloric acid. $11.6 \mathrm{M}$, reagent grade.

Thorium nitrate reference solution. Dissolve thorium metal in $\mathrm{HNO}_{3}$, evaporate the solurion to dryness, and dissolve the residue in water to a concent ration of $20-25 \mathrm{mg} \mathrm{Th} / \mathrm{g}$ of solution. The thorium is determined gravimetrically as the oxalate.

Xylenol orange. $0.1 \%$ in $20 \%$ ethanol.

\section{PROCEDURE}

1. Ignite carbide samples in a fused-silica or platinum dish in air at about $800^{\circ} \mathrm{C}$ to incinerate the carbon.

2. Iissolve the oxide or oxidized carbide sample by the sealed-reflux technique or transfer the sample by washing with water to a $100 \mathrm{~m} \ell$ beaker. Add 5 $\mathrm{m} \ell$ of $15.5 M \mathrm{HNO}_{3}, 10-20$ drops of $1.3 \mathrm{M} \mathrm{HF}$, and $5 \mathrm{~m} \ell$ of $70 \% \mathrm{HCLO}_{4}$. Evaporate the water at $\simeq 100^{\circ} \mathrm{C}$ on a hot plate or steam bath, cover the beaker with a watch glass, and heat until the sample dissolves.

3. Transfer the solution obtained by the sealedreflux technique by washing with water into a 100 m $\ell$ beaker. Evaporate the solution to dryness on a hot plate or steam bath. If the sample was dissolved in a beaker, rinse the watch glass, and allow the combined rinse and solution to evaporate to dryness.

4. Redissolve the residue in $1 M \mathrm{HCl}$.

5. 'Transfer aliquots containing 100-125 $\mathrm{mg}$ of ' $\mathrm{Th}$, preferably on a weight basis, to $50 \mathrm{~m} \ell$ beakers.

6. Evaporate the aliquots to dryness on a hot plate or steam bath.

7. (ool the sample residue and dissolve in $12 M$ H('l.

8. Transfer the solution quantitatively, using a minimum amount of $12 \mathrm{M} \mathrm{HCl}$, to a washed $5-\mathrm{m} \ell$ Bio-Rad A( $1-X 2$ anion-exchange resin column, and collect the eluate in a $100-\mathrm{m} \ell$ beaker.

9. Wash the column with a minimum of three column volumes* of $12 \mathrm{M} \mathrm{HCl}$.

10. Add $5 \mathrm{ml}$ of $70 \% \mathrm{HClO}_{4}$ and $2 \mathrm{ml}$ of $15.5 \mathrm{M}$ $\mathrm{HNO}_{3}$ to the eluate.

11. Evaporate the eluate slowly to dryness on a hot plate or steam bath and allow the residue to cool.

'A column volume is equal to the void volume if the column.
12. Dissolve the residue in a small amount of water and again evaporate to dryness.

13. Dissolve the residue in about $20 \mathrm{~m} \ell$ of wator and add $i s$ drops of $0.1 \%$ xylenol orange solution.

14. Stir the solution with a magnetic mixer and monitor the solution's $\mathrm{pH}$ with a combination electrode.

15. Maintain the $\mathrm{pH}$ of the solution at $2.5 \pm 0.1$ during the titration by adding dilute $\mathrm{NaOH}$ or $\mathrm{HCl}$ solution as required.

16. Titrate the thorium in the aliquot with $0.025 M$ EDTA (added from a weight burette) until the xylenol orange indicator turns yellow.

17. Titrate a thorium reference solution foilowing steps $1: 3$ through 16 to determine the EITA titer.

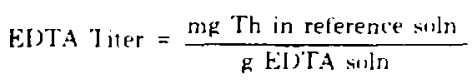

18. Calculate the thorium content of the sample as follows.

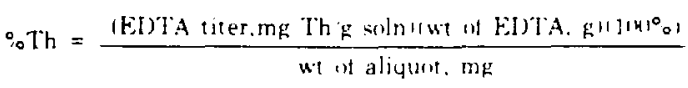

19. A blank correction is not required.

\section{EXPERIMENTAL}

\section{A. Thorium Reference Solutions}

Iron-free thorium reference solutions were prepared by dissolving the pure metal in $\mathrm{H}_{\mathrm{NO}}$. evaporating the solution to dryness, and dissolving the residue in water. The solutions were diluted to contain 2()$-25 \mathrm{mg}$ ' $\mathrm{Th} / \mathrm{g}$ of solution.

Weighed aliquots containing approximately 100 mg Th were titrated directly with the EDTA solution, with xylenol orange as the indicator. The end point (from purple to golden vellow) is sharp and easily seen. The EITA titer is determined from the results of three or more titrations against the reference solution. An average relative standard deviation (RSD) of $0.04 \%$ was found over 12 sets of 3 or more aliquots of reference solution as shown in Table 1 .

Data on prepared solutions containing both plutonium and thorium appear in Table II. After removal of plutonium, the average recovery for 


\section{TABLE I}

\section{THORIUM REFERENCE SOLUTIONS}

\begin{tabular}{cc}
$\begin{array}{c}\text { Aliquots } \\
\text { Analyzed }\end{array}$ & $\begin{array}{c}\text { EDCA titer } \\
\text { RSD }\end{array}$ \\
\hline & - \\
4 & $0.05 \%$ \\
4 & $0.013 \%$ \\
4 & $0.01 \%$ \\
3 & $0.06 \%$ \\
4 & $0.05 \%$ \\
4 & $0.01 \%$ \\
3 & $0.01 \% \%$ \\
4 & $0.010 \%$ \\
5 & $0.07 \%$ \\
4 & $0.01 \% \%$ \\
5 & $0.013 \%$ \\
10 & $0.05 \%$ \\
& $0.0 \% \%$
\end{tabular}

"Hecause the actual titer of EI)TA solution changes with time, unly these reference aliquents analyzed the same day can be com. piared. Fintries represent determinations done on different dals.

thorium as determined by titration is $99.98 \%$ with a RSID of $0.07 \%$. Since the recovery of thorium is quantitative, one can omit the elution of thorium reference solutions through the anion-exchange resin. Thus, one is able to standardize the EDTA titrant while other work is in progress.

\section{Blank}

A blank (no thorium or plutonium) was eluted through the ion-exchange column and titrated. It required an amount of EDTA equivalent to $0.006 \mathrm{mg}$ Th. This represents an error $<0.01 \%$ in a typical 100 -mg Th sample, which is far below the accuracy of the method. 'Thus, the bank correction is assumed to be zero in these studies.

\section{Samples}

Samples cont aining $100 \mathrm{mg}$ Th with or without 25 $\mathrm{mg} \mathrm{Pu}$ were analyzed as described in the procedure. On several samples, the eluate was collected in frac- tions, and each fraction was titrated separately. The results are shown in Table III. These tests indicate that three column volumes of eluent are needed to recover the thorium quantitatively.

\section{Precision}

Precision for reference solutions (0). $0.1 \%$ RSDI is better than for samples containing both 1 horium and phutonium (1).07\% RSID). Frrm in the weight of complexant added and rariation in $\mathrm{pH}$, which aflects the and point of the titration, are two sources of error in the determination. An error of $10 \mathrm{mg}$ in the addition of complexant int roduces a relative error of $0.07 \%$ in the determination of thorium.

\section{E. Columns}

Before use. the columns are packed with Bio-Rad $\mathrm{A}(\mathrm{i} 1 \mathrm{-X} 2$ anion-exchange resin dispersed in $1 \mathrm{M} \mathrm{HCl}$ and then rinsed with $5-10$ column volumes of $12 \mathrm{M}$ $H($ 'l. After the thorium is eluted, the plutonium may' be eluted from the resin with three column volumes of i $M \mathrm{HCl}$. 'The column is regenerated for the next sample or set of samples by rinsing with three column volumes of $12 \mathrm{M} \mathrm{HC}$ 'l. The amount of resin used in each column was estimated to sorb $1 \mathrm{~g}$ of l' $\mathrm{Pu}$. In practice. $100 \mathrm{mg}$ of $\mathrm{P} u$ did sorb at the top $15 \%$ of the bed volume. This permits the analysis of several samples before the resin becomes saturated and the plutonium has to be eluted.

\section{INTERFERENCE}

Interference from the cations of iron, zirconium. and zinc, which form stable complexes with EI)TA and from the anions $\mathrm{SO}_{4}=, \mathrm{PO}_{4} \equiv$, and $\mathrm{F}^{-}$. which form stable thorium complexes, was considered. Iranium, a likely impurity in the mixed oxide or carbide fuel. is removed along with plutonium by the ion-exchange resin column. ${ }^{2}$ Fluoride ion volatilizes when the samples are fumed to dryness with $\mathrm{HClO}$.

Interference was tested by adding the cation or anion to a sample containing $100 \mathrm{mg}$ Th. The sample was then analyzed as described in the procedure. At the $1 \%$ impurity level, cerium interferes with ine 
TABLE II

SAMPLE SIMULATION

\begin{tabular}{|c|c|c|c|c|}
\hline $\begin{array}{c}\text { EDTA Titer } \\
(\mathrm{mg} / \mathrm{g})\end{array}$ & $\begin{array}{c}\text { Pu in Sample } \\
\text { (mg) } \\
\end{array}$ & $\begin{array}{c}\text { Th in Sample } \\
\text { (mg) } \\
\end{array}$ & $\begin{array}{c}\text { wt of EDTA } \\
\text { (g) } \\
\end{array}$ & $\begin{array}{c}\text { Th recovery } \\
(\%)\end{array}$ \\
\hline 6.3013 & 24.2211 & 96.5393 & 15.3114 & 99.97 \\
\hline 6.303 & 24.3905 & 94.5559 & 14.9906 & 99.933 \\
\hline 6.30 .3 & 24.2443 & $96.54: 39$ & 15.3172 & 99.89 \\
\hline $6.30: 3$ & 24.4215 & 94.6084 & $15.0(0) 32$ & 99.95 \\
\hline 6.30 .3 & 21.2162 & 95.2838 & 15.1025 & 99.90 \\
\hline $6.30: 3$ & 24.6062 & 97.3866 & $15.452 \%$ & 100.01 \\
\hline $6.30: 3$ & 24.2724 & 97.3317 & 15.4490 & 1001.04 \\
\hline 6.3013 & 24.3857 & 95.7970 & 15.1867 & 99.92 \\
\hline 6.303 & 24.4268 & 97.2005 & $15.42: 30$ & 100.01 \\
\hline 6.247 & 24.7941 & 101.2687 & 16.1956 & 99.91 \\
\hline 6.247 & 24.1115 & 101.9995 & 16.33387 & 100.07 \\
\hline 6.247 & 24.4307 & $10: 1074$ & 16.1847 & 100.00 \\
\hline 6.247 & $24.2(990$ & $101.84(08$ & $16.3160)$ & 100.08 \\
\hline 6.247 & 24.4559 & 102.0600 & 16.3207 & 99.90 \\
\hline 6.247 & 24.1373 & 101.33317 & 16.2084 & 99.92 \\
\hline 6.247 & 24.0564 & 100.9742 & 16.0 .364 & 100.11 \\
\hline 6.247 & 24.3789 & 100.55330 & $16.092: 3$ & 99.98 \\
\hline 6.247 & $11.745 \mathrm{j}$ & 100.6765 & 16.1178 & 100.01 \\
\hline 6.239 & -.. & 100.8050 & 16.1711 & $1(00.01) 9$ \\
\hline \multirow[t]{2}{*}{$6.2: 39$} & $\cdots$ & 102.3800 & 16.4047 & 99.97 \\
\hline & & & & $\begin{array}{l}\text { Avg 99.98 } \\
\text { RSI) }(0.07 \%\end{array}$ \\
\hline
\end{tabular}

TABLE III

THORIUM ELUTION STUDY

\begin{tabular}{cc}
$\begin{array}{c}\text { Volume of } \\
\text { Eluent }^{\mathbf{a}}\end{array}$ & $\begin{array}{c}\text { Th Recovery (\%) } \\
\text { Volume of Eluent }^{\mathbf{b}}\end{array}$ \\
\cline { 1 - 2 } 1 & \\
2 & 35.46 \\
3 & 62.97 \\
$\mathbf{4}$ & 1.57
\end{tabular}

"Expressed in term of multiples of the roid volume of uhe column bach result is the average of three runs. 
TABLE IV

INTERFERENCE STUDY OF VARIOUS IONS

\begin{tabular}{|c|c|c|c|}
\hline \multirow[b]{2}{*}{ Ions Tested } & \multirow[b]{2}{*}{ Form Used } & \multicolumn{2}{|c|}{ Th Recovery $(\%) /$} \\
\hline & & $1.0 \%$ Level & $0.1 \%$ Level \\
\hline $\mathrm{Fe}^{+3}$ & $F e\left(i_{3} \cdot 6 H_{2} r\right)$ & 99.96 & Not tested \\
\hline$Z r^{+4}$ & $\mathrm{ZrOCl} \cdot 8 \mathrm{H}_{2} \mathrm{O}$ & 99.92 & 100.02 \\
\hline$\left(\mathrm{e}^{+4}\right.$ & $\left(\mathrm{NH}_{4}\right)_{2} \mathrm{Ce}\left(\mathrm{NO}_{3}\right)_{6}$ & 100.40 & 99.99 \\
\hline $\mathrm{SO}_{4}=$ & $\mathrm{H}_{2} \mathrm{SO}_{4}$ & 99.97 & 99.99 \\
\hline $\mathrm{PO}_{4} \equiv$ & $\mathrm{H}_{3} \mathrm{PO}_{4}$ & 96.11 & $1(0) .01$ \\
\hline
\end{tabular}

determination but iron and zirconium are removed by the ion-exchange column. Sulfate does not interfere at the $1.0 \%$ leiel but phosphate interferes by complexing with thorium, giving a low apparent recovery. None of the metals or anions tested interfered at the $0.1 \%$ level. Table IV summarizes the results of triplicate samples tested with the impurity at hoth the $1.0 \%$ and $0.1 \%$ level.

\section{REFERENCES}

1. .J. Korbl and R. Pribil, "Xylenol Orange: New Indicator for the EDTA Titration," ChemistAnalyst 45, 102 (1956).
2. ('W. (C. Milner and .J. L. Woodhead. "I he Volumetric Determination of Plutonium with Ethylenediaminetetraacetic Acid," Analyst. 81. 427 (1956).

3. A. D. Hues, A. 1. Henicksman, and W. H. Ashley. "Determination of L iranium and Thorium in (arbon and Silicon ('arbide-Coated I'raniumThorium carbide Fuel Beads," Los Alamos Scientific Laboratory report, LA-5429 (Octoher 197:3).

4. J. W. I)ahlby, R. R. Geoffrion, and (G. R. Waterbury, "The Sealed-Reflux Dissolution System." Los Alamos Scientific Laboratory report LA-5776 10ctober 1974). 